\title{
Prosodic and pragmatic properties of affirmative words in European Portuguese
}

\author{
Vera Cabarrão $^{1,2}$, Ana Isabel Mata ${ }^{1}$
}

${ }^{1}$ FLUL/CLUL, University of Lisbon, Portugal

${ }^{2}$ IST/INESC-ID, Lisbon, Portugal

https://doi.org/10.36505/ExLing-2012/05/0009/000215

\begin{abstract}
This paper investigates the correlation between the prosodic behavior and pragmatic functions of affirmative words from a spoken dialogue corpus collected for European Portuguese (EP). The analysis of 460 affirmative answers shows that affirmative words expressing agreement occur more often than those interpreted as auto positive and confirm. Low/falling and high/rising nuclear contours correlate with affirmative words with different pragmatic functions: agreement and confirm are commonly uttered with $(\mathrm{H}+) \mathrm{L}^{*} \mathrm{~L} \%$, whereas auto positive is commonly uttered with $\mathrm{L}^{*}+\mathrm{H} /(\mathrm{L}+) \mathrm{H}^{*} \mathrm{H} \%$. The analysis of acoustic/prosodic cues reveals that the three functions of the affirmative word sim 'yes' have significant differences $(p<.001$ and $p<.05)$. A pitch concord effect is also found between functions, although expressed in different degrees.
\end{abstract}

Key words: affirmative words, prosody, pragmatics, dialogues.

\section{Introduction}

Previous research has shown that (i) affirmative words are crucial in dialogues but also difficult to identify automatically, since they serve different communicative functions; and that (ii) the prosodic behavior of these structures varies according to their function (e.g., Benus et al. 2007; Gravano et al. 2007, 2012; Mata \& Santos 2011, a. o.). This study is a first attempt to characterize affirmative words in adult-adult interactions in EP. Our main goal is to verify if words such as sim 'yes', okay or humhum (grunts) correlate with different acoustic/prosodic cues depending on their communicative function.

\section{Methodology}

This study uses a subset of the CORAL corpus (Viana et al. 1998), comprising 11 dialogues (12 speakers, 5 male and 7 female) in Map-task format. We analyzed 460 affirmative answers, corresponding to several linguistic structures, namely: sim 'yes', okay, exacto 'exact', exactamente 'exactly', certo 'certainly', está bem 'that's right', está correcto 'that's correct', pronto, pois; grunts (e.g., humhum); the frozen form of the verb ser 'to be'; and both the repetition of the previous utterance, as well as the repetition of the main or auxiliary verb. These affirmative words occur mainly as isolated utterances $(\mathrm{N}=320)$, but also at the beginning $(\mathrm{N}=91)$, in the middle $(\mathrm{N}=18)$, and at the end of longer utterances $(\mathrm{N}=31)$.

ExLing 2012: Proceedings of 5th Tutorial and Research Workshop on Experimental Linguistics, 27-29 August 2012, Athens, Greece 
Affirmative words were classified as proposed by the Semantic Annotation Framework - Part 2: Dialogue Acts, developed by Bunt et al. (2010) according to the rules of the International Organization Standard (ISO). The data was coded with three communicative functions: agreement (AG) - the speaker accepts the previous utterance as true; auto positive (AuP) - the signal was well interpreted and the listener is still paying attention; and confirm (CONF) - answers to yes-no questions and check questions.

The prosodic annotation was done in the ToBI (Tones and Break Indices) system, applying the first proposal Towards a P_ToBI (Viana et al 2007). For each affirmative word and for their adjacent declarative and interrogative contexts, we extracted the following features: number of syllables, duration (ms), energy mean, pitch maxima, minima and range, as well as $f_{0}$ values corresponding to high $(\mathrm{H})$ and low $(\mathrm{L})$ targets within the nuclear pitch accents and final boundary tones. All $f_{0}$ values were converted to semitones (ST).

\section{Results}

\section{Affirmative words and communicative functions}

Results show that affirmative words expressing agreement occur more often (52\%) than affirmative words interpreted as auto positive (28\%) and confirm (20\%). The most common affirmative structures in the corpus are: sim 'yes' (42.8\%), used across all functions $(\mathrm{N}=197: \mathrm{AuP}=81, \mathrm{AG}=78, \mathrm{CONF}=38)$; okay (16.3\%), mainly classified as agreement $(\mathrm{N}=75$ : $\mathrm{AG}=58)$; and grunts (10.7\%), mainly coded as auto positive $(\mathrm{N}=49$ : $\mathrm{AuP}=31)$. Affirmative words such as exacto 'exact', exactamente 'exactly', and está bem 'that's right' (mainly classified as agreement or confirm) are quite residual in the corpus.

\section{Prosodic properties}

Results from a Kruskal-Wallis test show that the three functions of the affirmative word sim 'yes', as an isolated utterance, differ significantly in the following properties: duration $\left(\chi^{2}(2)=13.093, p<.001\right), f_{0}$ mean $\left(\chi^{2}(2)=6.583\right.$, $p<.05)$, maxima $\left(\chi^{2}(2)=8.172, p<.05\right)$, and minima $\left(\chi^{2}(2)=8.243, p<.05\right)$. This affirmative word has, therefore, a different prosodic behavior according to its different functions: (i) as auto positive, it correlates with higher values of duration, $f_{0}$ mean, maxima and minima; (ii) as confirm, it presents the lowest values of duration, $f_{0}$ mean, maxima, and minima, but the highest energy value; and (iii) as agreement, it presents the lowest energy value and, in all the remaining features, it is closer to the auto positive function. 

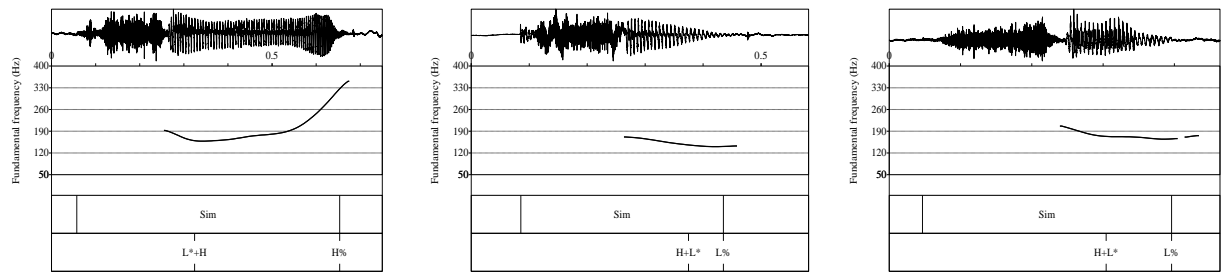

Figure 1. Sim 'yes' coded as agreement, as confirm, and as auto positive.

As for nuclear pitch accents and boundary tones across all functions (Table 1), results point out that low/falling and high/rising nuclear contours correlate with affirmative words with different pragmatic functions. Two distinct trends were found in the data: (i) agreement and confirm are commonly uttered with low/falling nuclear contours ( $\mathrm{L}^{*} / \mathrm{H}+\mathrm{L}^{*} \mathrm{~L} \%$ ), indicating completeness; (ii) auto positive is mainly uttered with high/rising nuclear contours $\left(\mathrm{H}^{*} / \mathrm{L}^{*}+\mathrm{H} / \mathrm{L}+\mathrm{H}^{*} \mathrm{H} \%\right)$, suggesting continuation. These results are comparable with what Benus (2007) and Gravano (2012) found for English. Thus, results show that different pragmatic functions are associated with distinct prosodic properties, making, therefore, a distinction between auto positive, on one hand, and agreement and confirm, on the other. See Figure 1.

Table 1. Distribution of nuclear pitch accents and boundary tones.

\begin{tabular}{|c|c|c|c|c|c|c|c|c|c|}
\hline \multirow{3}{*}{ Functions } & \multicolumn{6}{|c|}{ Nuclear pitch accent } & \multicolumn{3}{|c|}{ Boundary tones } \\
\hline & \multicolumn{2}{|c|}{ low/falling } & \multicolumn{3}{|c|}{ high/rising } & \multirow{2}{*}{$\mathbf{N}$} & \multirow{2}{*}{$\begin{array}{c}\text { low } \\
\text { L-/L \% }\end{array}$} & \multirow{2}{*}{$\begin{array}{c}\text { High } \\
\text { H-/H\% }\end{array}$} & \multirow{2}{*}{$\mathbf{N}$} \\
\hline & $\mathbf{L}^{*}$ & $\mathbf{H}+\mathbf{L}^{*}$ & $\mathbf{H}^{*}$ & $\mathbf{L}^{*}+\mathbf{H}$ & $\mathbf{L}+\mathbf{H}^{*}$ & & & & \\
\hline $\mathbf{A G}$ & 94 & 64 & 39 & 36 & 6 & 239 & $36 / 117$ & $12 / 74$ & 239 \\
\hline AuP & 26 & 23 & 27 & 49 & 4 & 129 & $5 / 41$ & $5 / 78$ & 129 \\
\hline CONF & 20 & 34 & 18 & 16 & 4 & 92 & $11 / 40$ & $9 / 32$ & 92 \\
\hline $\mathbf{N}$ & 140 & 121 & 84 & 101 & 14 & 460 & $52 / 198$ & $26 / 184$ & 460 \\
\hline
\end{tabular}

Additionally, we made a first analysis of the prosodic adjacent declarative and interrogative contexts of the affirmative words to check for the absence/presence of pitch concord effects. In isolated affirmative words, results suggest the presence of a pitch concord effect between the $\mathrm{H}$ targets of the declarative contexts and the $\mathrm{H}$ targets of the agreement and auto positive functions, although manifested in different correlations between nuclear pitch accents and boundary tones. For words classified as agreement, with a rising nuclear contour, the correlation is significant: (i) between the $\mathrm{H}$ target of the falling nuclear accent of the context and the $\mathrm{H}$ target of the accent of the affirmative word $\left(\mathrm{r}_{\mathrm{s}}=.435, p<.05\right)$; and (ii) between the $\mathrm{H}$ target 
of the high boundary tone of the context and the $\mathrm{H}$ target of the boundary tone of the affirmative word $\left(\mathrm{r}_{\mathrm{s}}=.416, p<.01\right)$. For words coded as auto positive, with a rising nuclear contour, the correlation is significant between the $\mathrm{H}$ targets of the high boundary tone of the context and (i) the $\mathrm{H}$ target of the nuclear accent of the affirmative word $\left(\mathrm{r}_{\mathrm{s}}=.245, p<.05\right)$; and (ii) the $\mathrm{H}$ target of the boundary tone of the affirmative word $\left(\mathrm{r}_{\mathrm{s}}=.570, p<.01\right)$. For the confirm function and for interrogative contexts, no correlations were found.

\section{Conclusions}

Results show that agreement is the most frequent function in the corpus, followed by auto positive and confirm. Regarding the prosodic properties of the affirmative words, we can make two generalizations: low/falling contours, indicating completeness, mainly occur in affirmative words classified as agreement and confirm; and high/rising contours, suggesting continuation, are more frequent in words classified as auto positive. The prosodic properties point out to the different prosodic behavior of the affirmative word sim 'yes' according to its function. There are also evidences of a cross function effect of pitch concord between declarative contexts and affirmative words, although expressed in different degrees.

\section{Acknowledgements}

This work was supported by national funds through FCT - Fundação para a Ciência e a Tecnologia - under the project PTDC/CLE-LIN/120017/2010, and by PEst-OE/EEI/LA0021/2011.

\section{References}

Benus, S., Gravano, A. and Hirschberg, J.. 2007. The prosody of backchannels in American English. In Proceedings ICPhS XVI, Saarbrücken: 1065-1068.

Gravano, A., Hirschberg, J., Benus, S. 2012. Affirmative cue words in task-oriented dialogue. Computational Linguistics. Vol. 38(1), pages 1-39

Mata, A., Santos, A. 2011. Intonation of Early Answers to Confirmation-Seeking Questions in Spontaneous Speech, BUCLD 35 Proceedings, Cascadilla Press.

Viana, M.C., Trancoso, I., Mascarenhas, I., Duarte, I., Matos, G., Oliveira, L., Campos, H., Correia, C. 1998. Apresentação do projecto Coral - corpus de diálogo etiquetado. In Workshop de Linguística Computacional. Lisbon, Portugal .

Viana, C., Frota, S., Falé, I., Fernandes, F., Mascarenhas, I., Mata, A., Moniz, H. and Vigário, M.. 2007. Towards a P_ToBI. PAPI2007. Workshop on the Transcription of Intonation in Ibero-Romance. Universidade do Minho. 